\title{
Turbocharging of engines with low cylinder numbers: a thermodynamic consideration
}

\author{
Georg Kellermayr $^{1} \cdot$ Eberhard Schutting ${ }^{1} \cdot$ Horst Mitterecker $^{2}$
}

Received: 21 January 2019 / Accepted: 26 June 2019 / Published online: 29 July 2019

(c) The Author(s) 2019

\begin{abstract}
In the present investigation, the influence of the number of cylinders on the turbocharger and the pumping losses were determined by extensive simulations in combination with experimental investigations. The turbine efficiency is influenced by the different pulsations as a function of the number of cylinders. In addition, another very serious influence of the number of cylinders on the pumping losses has been found. This effect depends strongly on the exhaust volume before turbine, which is why the topic of constant pressure and pulse turbocharging must be considered in detail. It has been found that a smaller number of cylinders $(<4)$ has higher pumping losses in principle, even with the same turbocharger efficiencies. The lowest pumping losses can be achieved with four-cylinder engines. It has also been shown that this issue is completely different for diesel and gasoline engines.
\end{abstract}

Keywords Pulse turbocharging $\cdot$ Pulsating turbine mass flow $\cdot$ Two-cylinder turbocharging

\section{List of symbols}

$A_{\mathrm{T}} \quad$ Turbine cross-section

$c_{p} \quad$ Heat capacity

$\eta \quad$ Efficiency

$\lambda$ Stoichiometric air-to-fuel ratio

$m_{\mathrm{F}} \quad$ Fuel mass per stroke

$n \quad$ Engine speed

$p \quad$ Pressure

$T \quad$ Temperature

V Volume

Abbreviations

BDC Bottom dead centre

C Compressor

CA Crank angle

CPT Constant pressure turbocharging

Cyl Cylinder

Georg Kellermayr

g_kellermayr@yahoo.de

Eberhard Schutting

Schutting@ivt.tugraz.at

Horst Mitterecker

Horst.Mitterecker@avl.com

1 Institute of Internal Combustion Engines and Thermodynamics, Graz University of Technology, Graz, Austria

2 AVL-List GmbH, Graz, Austria

$\begin{array}{ll}\text { D } & \text { Displacement } \\ \text { EGR } & \text { Exhaust gas recirculation } \\ \text { EO } & \text { Exhaust open } \\ \text { EX } & \text { Expansion } \\ \text { Exh } & \text { Exhaust } \\ \text { HP } & \text { High pressure } \\ \text { IMEP } & \text { Indicated mean effective pressure } \\ \text { Int } & \text { Intake } \\ \text { LP } & \text { Low pressure } \\ \text { PMEP } & \text { Pumping mean effective pressure } \\ \text { TDC } & \text { Top dead centre } \\ \text { TC } & \text { Turbocharger }\end{array}$

Subscripts

1 Compressor inlet

2 Compressor outlet

3 Turbine inlet

4 Turbine outlet

$\mathrm{s} \quad$ Isentropic

t Total

$\mathrm{T} \quad$ Turbine

\section{Introduction}

Turbocharging was a key factor for increased use of engines with low displacement and low number of cylinders at a high power output. As an advantage of engines with lower 
displacement and less cylinders, both the higher efficiency and the smaller packaging can be mentioned. In gasoline passenger car applications, there has been a clear trend from fourcylinder engines to three-cylinder engines in the past, but there has been no definite trend in the diesel engine segment. In off-road applications, the use of three-cylinder diesel engines continues to increase, and even two-cylinder engines are in series production $[4,10]$.

The disadvantage of engines with low cylinder numbers is the long firing interval and the associated high pulsations in the exhaust manifold. Strong pressure and mass flow pulsations influence the efficiency of the turbocharger. Turbomachinery usually prefers constant inlet and outlet conditions. The combination with a reciprocating piston engine leads to unfavourable conditions depending on the operating point, the number of cylinders and the exhaust system. There are many publications concerning turbine efficiency under pulsating conditions. In the present study, the differences between a four-cylinder and a two-cylinder engine with respect to turbocharging should be investigated. In addition to the influence on the turbocharger efficiency, another very interesting effect on the pumping losses was found.

\section{Methodology}

The subject of turbocharging with low cylinder numbers was investigated both with 1D-CFD simulations and on an engine test bench. The simulations were done with the commercial program AVL-BOOST. A four-cylinder passenger car diesel engine with a displacement of 1.61 was used as the test carrier. The two-stage charging system of this test carrier consisted of two turbochargers with fixed turbine geometry. The high-pressure turbine can be bypassed for boost pressure control in two-stage turbocharged operation. In addition, the low-pressure turbine is equipped with a wastegate, so that boost pressure control can also be realized in single-stage operation (high engine speeds).

Simulations with constant turbocharger efficiency showed the influence of the number of cylinders and the exhaust volume. However, the influence of the pulsating mass flow on the turbine efficiency can not be sufficiently determined without measurements. In the experiment, the four-cylinder engine was operated as a two-cylinder engine by the use of modified camshafts. Using the combination of measurement and simulation, it was possible to determine the influence of the pulsating mass flow on the efficiency of the turbocharger.

\section{Simulation}

The model for the variation of the exhaust volume is shown schematically in Fig. 1. For each number of cylinders, the same cylinder geometry and displacement were used (identical cylinders). With this approach, effects of the cylinder and port geometry can be excluded. Additionally, the wall heat losses are identical, assuming the same cylinder filling.

An intake plenum of 301 ensured equal conditions for all variants. The pressure loss of the aftertreatment system was adapted to get identical pressure boundaries downstream turbine.

The used turbocharger model was a simplified model. This means that the efficiency of the turbocharger is constant and does not depend on the pressure ratio. The efficiency was chosen to be $49 \%\left(\eta_{\mathrm{C}}=70 \%\right.$ and $\eta_{\mathrm{T}}=70 \%$ ), a rather good efficiency in passenger car applications. The turbine size was adjusted to achieve the desired boost pressure. There is no wastegate mass flow, the entire mass flow passes the turbine. Heat loss in the exhaust gas duct has been deactivated, so an increased heat dissipation with a large manifold volume is not taken into account. It should be noted that the exhaust volume always represents the entire volume of ports, manifold and the turbine volute. The significant influence of the volute is shown in [1] and has to be considered.

Figure 2 shows gas exchange loops of four- and two-cylinder engines with two different exhaust volumes. The picture on the left shows a very low exhaust volume of 0.021 , which would be practically impossible to implement, but feasible in simulation. The operating point corresponds to $2.5 \mathrm{bar}$ boost pressure, an injection quantity of $50 \mathrm{mg} / \mathrm{str}$ at an engine speed of $2000 \mathrm{~min}^{-1}$. Both cylinder configurations show a positive gas exchange loop. The mutual influence of the individual cylinders based on the blow-down pulse at short ignition intervals (four-cylinder) has a strong effect on the residual gas content, but has relatively little effect on the pumping work. Even with the four-cylinder engine, the blow-down pulse comes too late or the ignition interval

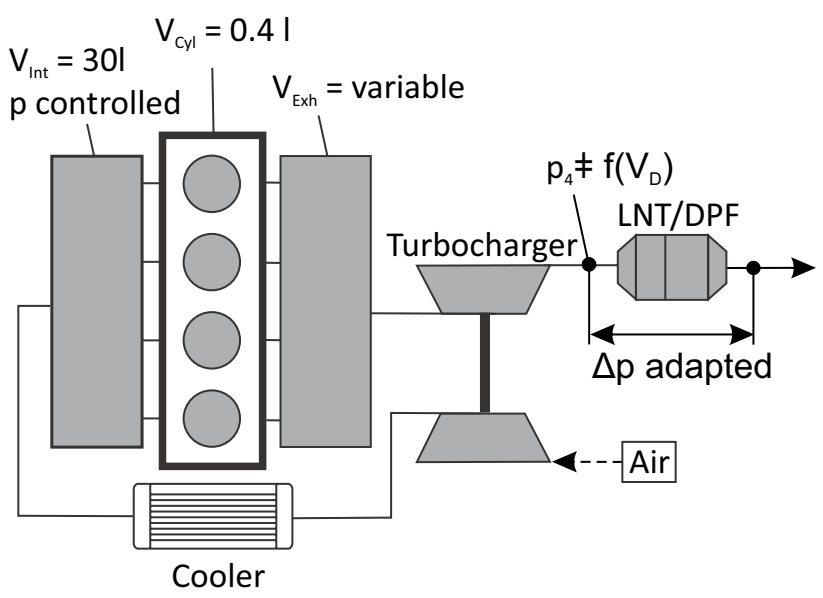

Fig. 1 Schematic model for exhaust volume variation 
Fig. 2 Pumping losses depending on the exhaust volume
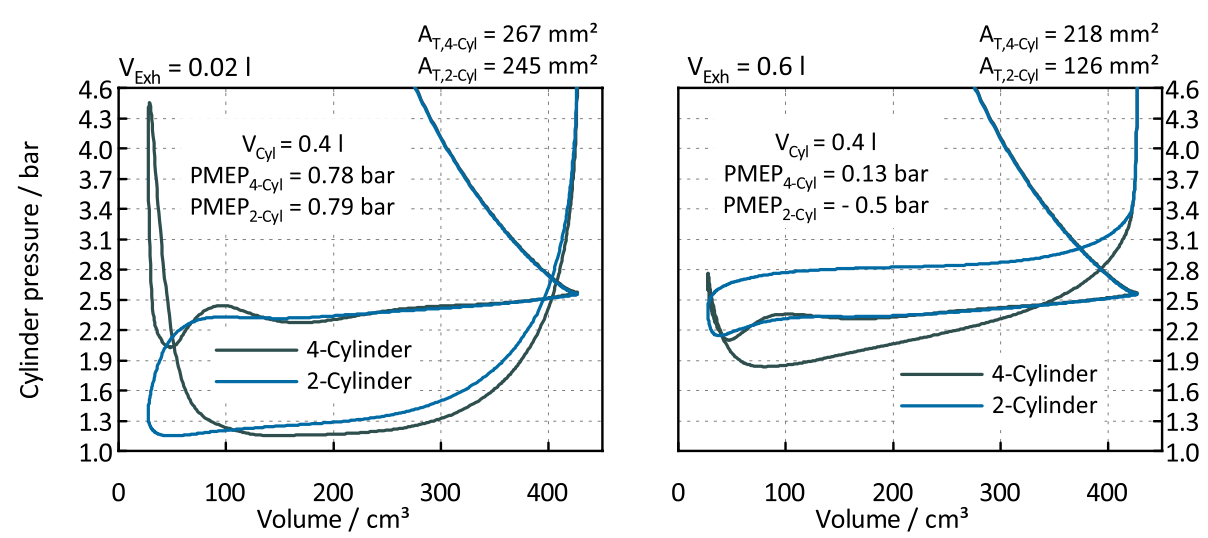

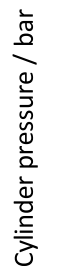

is long enough not to significantly influence the pumping work. Therefore, the pumping mean effective pressure (PMEP) of the two-cylinder engine and the four-cylinder engine is nearly identical. The necessary effective turbine size is almost equal, although the total engine displacement and consequently the exhaust gas flow rate are different by a factor of two. This fact was also mentioned in $[3,5]$.

In the picture on the right, the exhaust volume has been increased to a more realistic value of 0.61 . Beyond that, no parameter was changed, so that boost pressure, injection quantity and turbocharger efficiency are identical, yet the result is completely different. The PMEP of the two-cylinder engine is about 0.6 bar lower/worse than the PMEP of the four-cylinder engine. The necessary effective turbine crosssection is more in line with the general expectations that it would have to be significantly below or almost halved due to the lower overall displacement of the two-cylinder engine. The comparison between different numbers of cylinders is therefore very much dependent on the selected exhaust volume.

The exhaust volume was varied over a wide range with the simulation model for the two-, three- and four-cylinder configuration (Fig. 3). Looking at the course of the PMEP of the four-cylinder engine, one recognizes a tendency, which would also be expected with the knowledge from literature regarding constant pressure and pulse turbocharging. With the lowest exhaust volume, the highest PMEP is obtained. The PMEP then decreases with increasing exhaust volume and approaches the value of the constant pressure turbocharging.

What is not known from literature is the comparison with an engine with less cylinders. In these cases, the PMEP is approximately the same with pure pulse turbocharging, but it decreases significantly faster with increasing exhaust volume and also achieves lower values than the four-cylinder engine can ever attain. A local minimum of the PMEP can be seen particularly well on the two-cylinder engine. As the volume is further increased, the PMEP rises again and approaches the four-cylinder values.

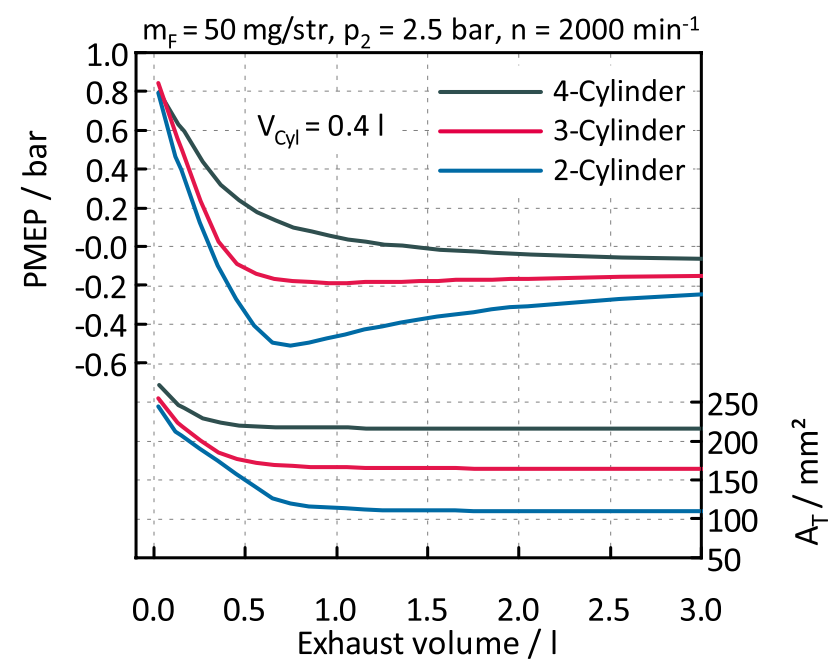

Fig. 3 Variation of the exhaust volume before turbine

In these simulations, the turbine size has always been adjusted so that a boost pressure of 2.5 bar is available in the intake plenum. The turbine size is very similar for all cylinder configurations with pure pulse turbocharging. Slight differences come from gasdynamic effects during scavenging.

As soon as the exhaust volume increases, the turbine size must be reduced to maintain the desired boost pressure. The lower the number of cylinders, the higher the reduction of the turbine size needs to be. Constant pressure turbocharging leads to a result, which is likely to meet most expectations. The two-cylinder engine with 0.81 total displacement requires exactly half the effective turbine cross-section as a four-cylinder engine with 1.61 total displacement.

Thus, it should be noted that pure pulse turbocharging requires a turbine size which has to be designed only for the single cylinder displacement, while a pure constant pressure turbocharging requires a turbine size depending only on the total displacement of the engine.

Based on the course of the turbine size, it can also be determined in which area an increased exhaust volume can 
have an influence on the boost pressure. For example, as the exhaust volume increases by 11 , starting from 11 and the four-cylinder engine, almost no change in the required turbine size is visible. As a result, even without changing the turbocharger, the same boost pressure would still be achievable. This situation looks completely different with lower exhaust volume or less cylinders. For example, if you were to make an increase of 11 on a two-cylinder engine based on an exhaust volume of 0.51 , a much smaller turbine would be required. Or in other words, with the same turbocharger, a much lower boost pressure would be generated with the larger exhaust volume.

Considering the exhaust volume at the minimum PMEP, another important aspect of the two-cylinder engine can be shown. At this exhaust volume, the turbine size needs to be bigger than with a larger exhaust volume. This circumstance in turn means that when operating a turbocharger with a very high exhaust volume and once with an exhaust volume of about 0.61 , with the smaller exhaust volume a higher boost

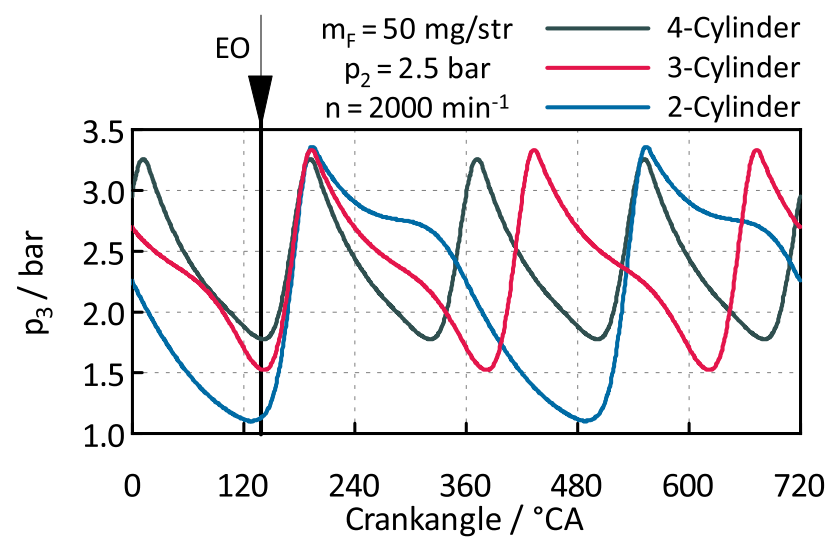

Fig. 4 Pressure pulsations with different cylinder numbers pressure could be generated, although the efficiency (PMEP) is lower. Therefore, it can not be concluded that a higher efficiency is present if a higher boost pressure is reached, since this higher boost pressure must be paid by increased gas exchange work.

Figure 4 shows the pressure pulsations with different number of cylinders and the same exhaust volume (0.6 l). The lower the number of cylinders or the longer the ignition interval, the higher the pressure pulsations in the exhaust manifold are. These pulsations can significantly effect turbine efficiency, but in previous simulations the turbocharger efficiency was kept constant. The reason for this behaviour (Fig. 3, PMEP over exhaust volume) can not be explained by the efficiency of the turbocharger.

\subsection{Cylinder discharge process}

The understanding of the different pumping losses depending on the exhaust volume as well as the number of cylinders requires a precise theoretical consideration of the discharge process.

In principle, the exhaust process can be divided into two phases, the blow-down phase and the push-out phase. Figure 5 illustrates the differences based on a real engine process. In an idealized engine process, the power stroke takes place from the ignition TDC to the following BDC, with closed valves. At BDC (time $t_{1}$ ), there is still a pressure above ambient in the cylinder. The exhaust valves open and a pressure equalization between cylinder pressure and exhaust back pressure occurs, while the piston stops in BDC-the blow-down phase. As long as the cylinder pressure is higher than the pressure in the exhaust manifold, gas flows through the turbine, thereby generating work. In this phase, no mechanical work is necessary for the discharge process. The
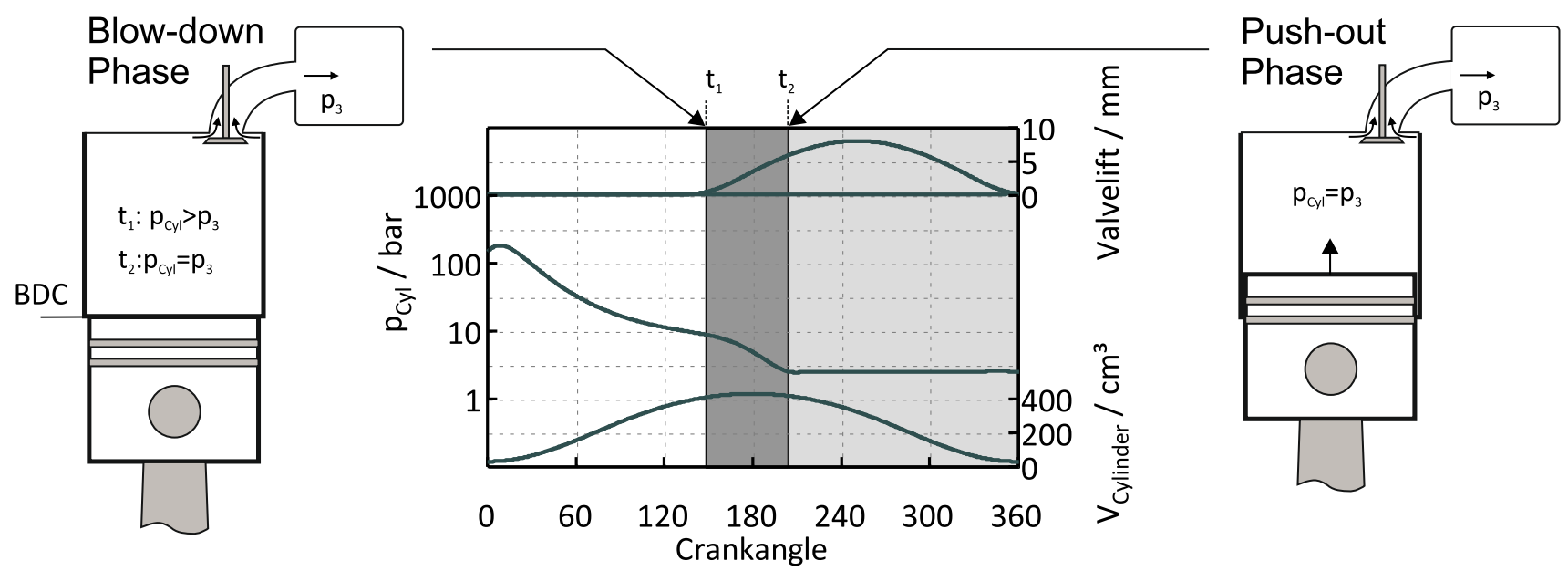

Fig. 5 Cylinder discharge phases 
displacement work done by the working gas in the cylinder is for free, so to speak- the basic idea of turbocharging.

After pressure equalization (from time $t_{2}$ ), the push-out phase begins. The piston moves at constant pressure towards TDC, the displacement work against the pressure $p_{3}$ must be expended by the crank drive.

The diagram in Fig. 5 shows valve lift, cylinder pressure and cylinder volume over crank angle. These data come from a BOOST simulation with a very large exhaust volume. In contrast to an idealized engine process, the distinction between the two exhaust phases is more difficult in a real process. The exhaust valve already opens before the BDC is reached and before the pressure equalization is completed, the piston is already in the upward movement. With smaller exhaust volumes and the resulting pressure pulsations in the exhaust manifold, the distinction is even more difficult or blurred.

Often, the subject of constant pressure and pulse turbocharging is explained by the conservation of the kinetic energy of the outflowing gas. This thermodynamic explanation can be found in, for example, [8]. Figure 6 shows simulation results of the 0.81 two-cylinder engine with a small exhaust volume. It is a simulation adapted to the measurements, as described in Fig. 18, that is anticipated for this explanation.

The total pressure and the gas velocity refers to a volute entry diameter of about $23 \mathrm{~mm}$, which can be considered rather low due to the two-stage charging and the small HP turbocharger. Thus, especially in this configuration, the effects of the dynamic pressure should be clearly visible. Nevertheless, the influence seems to be rather low, and the total pressure is on average $1.85 \%$ higher than the static pressure (related to the relative pressure).

Figure 7 shows the gas velocity curves in the valve gap and at the inlet of the turbine volute. This illustration shows that despite the low volume and small volute diameter, only

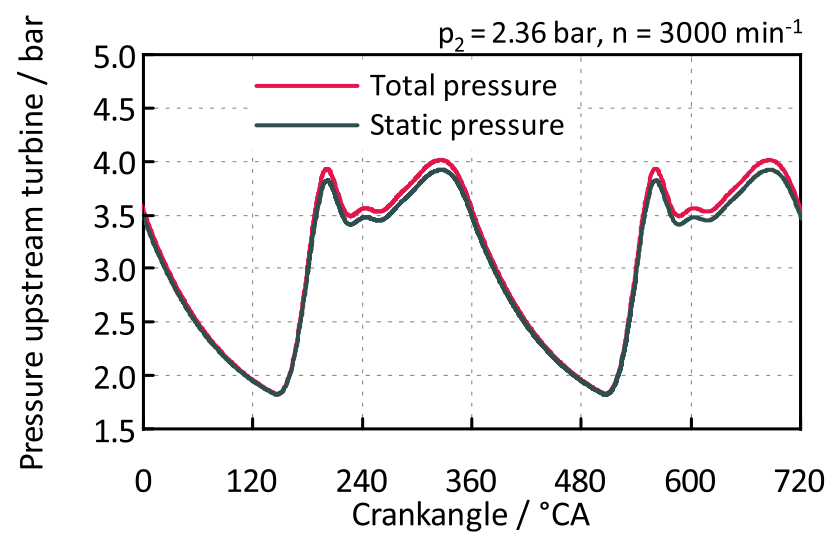

Fig. 6 Comparison of total and static pressure in the volute a fraction of the kinetic energy occurring in the valve gap can be retained.

But this consideration has a weak point that even with an ideal constant pressure turbocharging, a dynamic pressure component occurs. Even if the entire kinetic energy is dissipated in a large plenum, a certain flow velocity must occur in the turbine volute, depending on mass flow, pressure and temperature. This is therefore not a suitable measure for the conservation of the kinetic energy. Ultimately, the effect of this velocity preservation can be considered low, in contrast to a generally available opinion.

In any case, it should be noted that during the discharge process, the total enthalpy must remain constant (adiabatic throttle). In the following explanations, the velocity term is no longer considered, the pressures thus correspond to total pressures.

\subsection{Effect of the exhaust volume on the entropy}

The preservation of the kinetic energy could neither explain the large differences in the PMEP over the exhaust volume of Fig. 3, nor the dependencies on the number of cylinders. To understand these relationships, it is necessary to take a closer look at the discharge of the cylinder, first with constant pressure turbocharging.

The outflow during the blow-down phase is described in detail in Fig. 8. The exhaust valve opens at BDC (EO, time $a$, filling state of the cylinder: $100 \%$ ). As a result, gas flows out of the cylinder and expands to the pressure $p_{3}$, leaving the total enthalpy unchanged, but with a strong entropy increase. Due to the escaping gas mass, the gas mass in the cylinder is decreasing. Thus, the remaining gas in the cylinder is expanding isentropic. At time $b$, the temperature and the enthalpy in the cylinder have dropped, which is why the outflowing total enthalpy is now lower than at time $a$. This process continues until a pressure equalization is achieved and the cylinder pressure is equal to the pressure $p_{3}$ in the

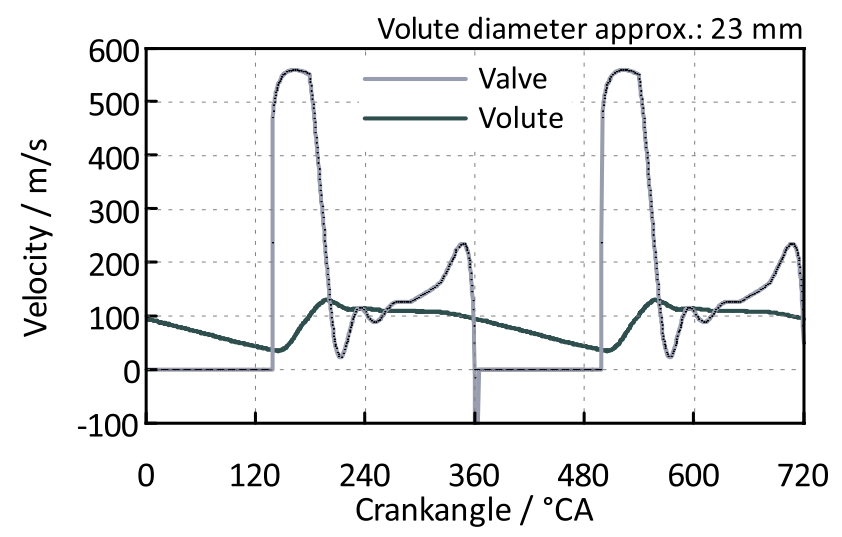

Fig. 7 Comparison of gas velocities, volute and valve 
$\mathrm{h}$

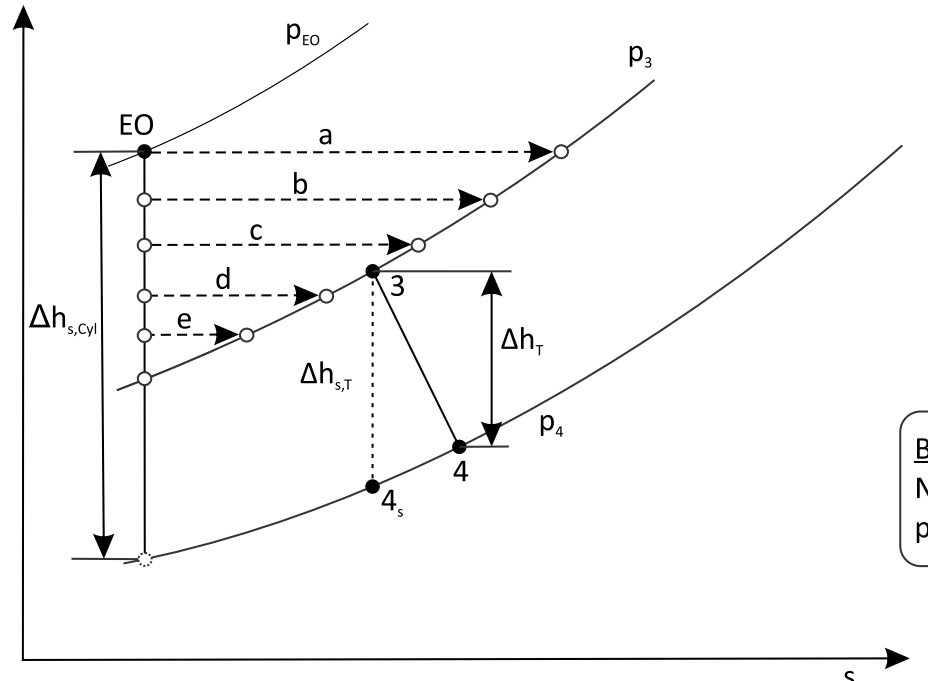

thas mass incylinder

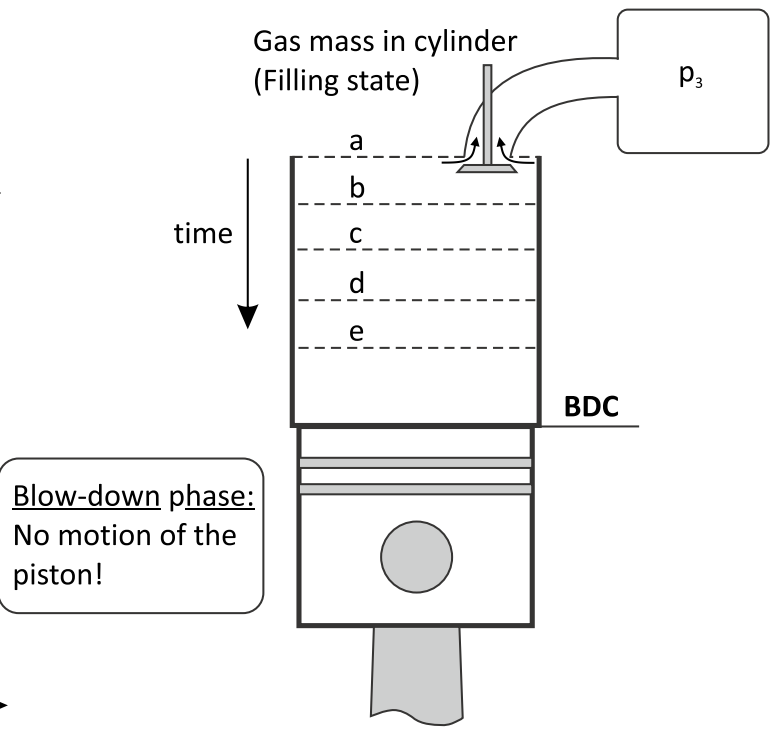

Fig. 8 Exhaust process with constant pressure turbocharging

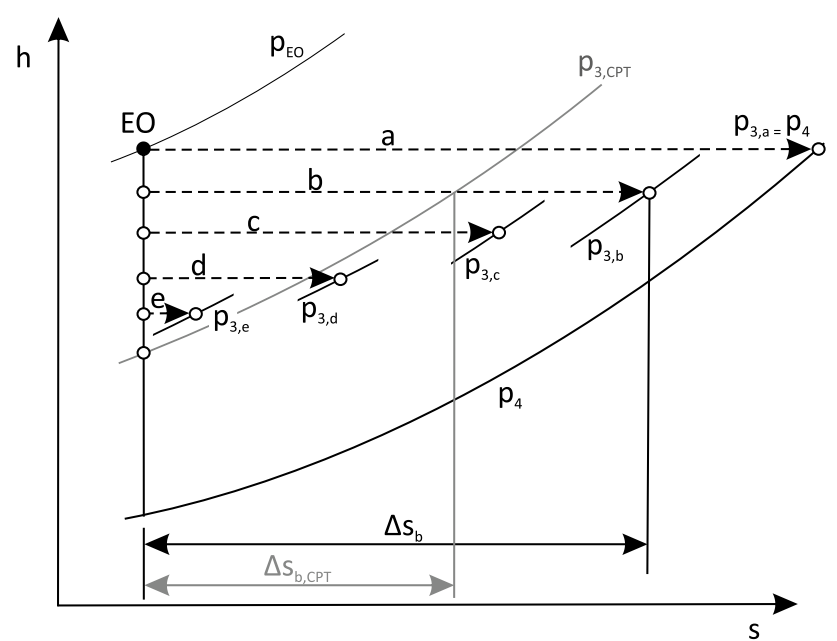

Fig. 9 Exhaust process with mid-size exhaust volume

exhaust manifold (exhaust stroke not shown in diagram). The average state in the exhaust manifold is marked with point 3 (which would also have to consider the exhaust stroke). This representation is also included in [9]. In addition, it is also explained how to analytically calculate point 3 .

The same way of representation is now used for the explanation of pulse turbocharging. Figure 9 shows the principle of pulse turbocharging with an unfavourably large exhaust volume in the $h-s$ diagram.

First of all, it is important to recall the pressure traces in the exhaust manifold from Fig. 4. As an example, the two-cylinder engine is used here. Between two exhaust events, the exhaust back pressure drops to ambient pressure (or the pressure downstream turbine), at least with good turbocharger efficiency. This means that the exhaust manifold has been emptied until the next cylinder starts the exhaust process.

In Fig. 9, it can therefore be seen that the very first exhaust process at time $a$ corresponds to an expansion up to the pressure downstream turbine. The maximum possible entropy increase occurs. The mass flowing into the manifold is greater than the mass flow through the turbine-the pressure build up in the manifold begins. At time $b$, the pressure in the exhaust volume has already increased somewhat, but the entropy increase is still higher than it would be the case with a constant pressure turbocharging. It depends on the exhaust volume, how fast a higher pressure than the pressure with constant pressure turbocharging (and thus a higher efficiency) can be reached. In the present example, a higher efficiency than constant pressure turbocharging is achieved only by time $e$.

A more favourable case is shown in Fig. 10. This picture corresponds to a small exhaust volume. At time $a$, the gas is again expanded to the ambient pressure, as in the previous picture. However, the pressure build up is much faster due to the small volume, the expansion at time $b$ already achieved a lower entropy increase than the constant pressure turbocharging. This finding explains the drop in the PMEP over the exhaust volume.

The local minimum of the PMEP on the two-cylinder engine can be explained as follows: the PMEP falls further and further because the pressure build up in the exhaust volume takes longer and longer. At some point, however, the volume is so big that the pressure between two exhaust events no longer drops to ambient pressure. Therefore, 


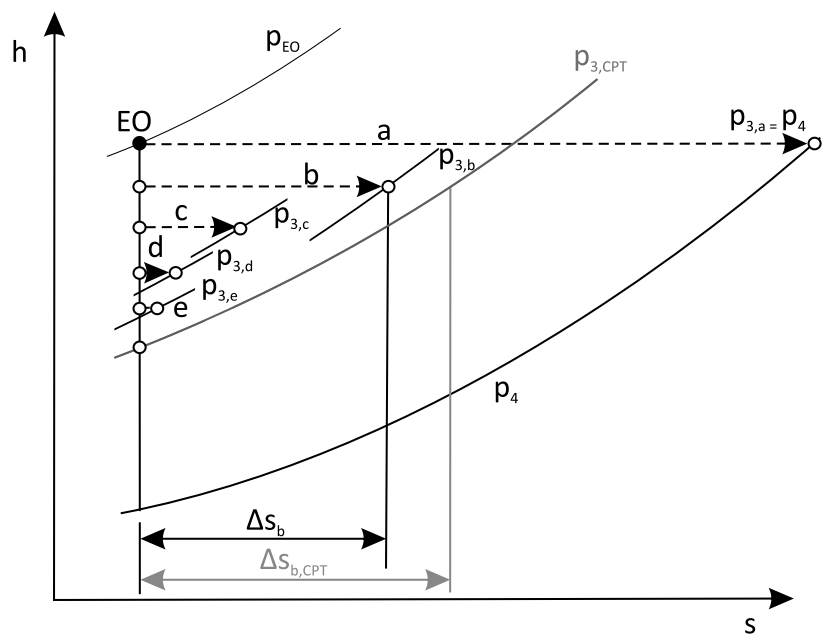

Fig. 10 Exhaust process with small exhaust volume

the PMEP then increases again and approaches the value related with constant pressure turbocharging.

Now the correlation between PMEP and the number of cylinders remains open. In principle, it is the same effect again. The pressure traces in the exhaust manifold from Fig. 4, with the different cylinder numbers, must be recalled again. The pressure drop in the exhaust volume to ambient pressure occurs only with the two-cylinder engine. On the three-cylinder engine, the firing interval is already too short. The four-cylinder engine has the shortest firing interval in this comparison, which is the reason why the pressure in the exhaust volume drops the least.

In Fig. 11, the very first exhaust operation is shown schematically. The three-cylinder engine expands the gas in the cylinder to a higher pressure than the two-cylinder engine and the four-cylinder engine to an even higher pressure. And so it is also in terms of entropy increase.

Figure 12 shows the influence of the injection quantity on the curves of the PMEP over exhaust volume. The injection quantities are shown in the picture. Since no EGR was used, lambda values describe the ratio of cylinder charge mass to fuel mass.

The lower the air/fuel ratio is chosen, the lower the pumping losses are. Furthermore, the curves shift towards larger exhaust volumes. Considering, for example, the minimum of the curve of the two-cylinder engine, this is approximately at a volume of 0.41 for an injection quantity of $35 \mathrm{mg}$ and at a volume of 1.41 for twice the injection quantity. This also means that at a lambda value of 1 and a very low but quite realizable exhaust volume, between the four- and three-cylinder engine almost no and compared to the two-cylinder engine, only a small difference occurs. On the other hand, the different pumping losses at higher lambda values cannot be avoided with any feasible exhaust volume.

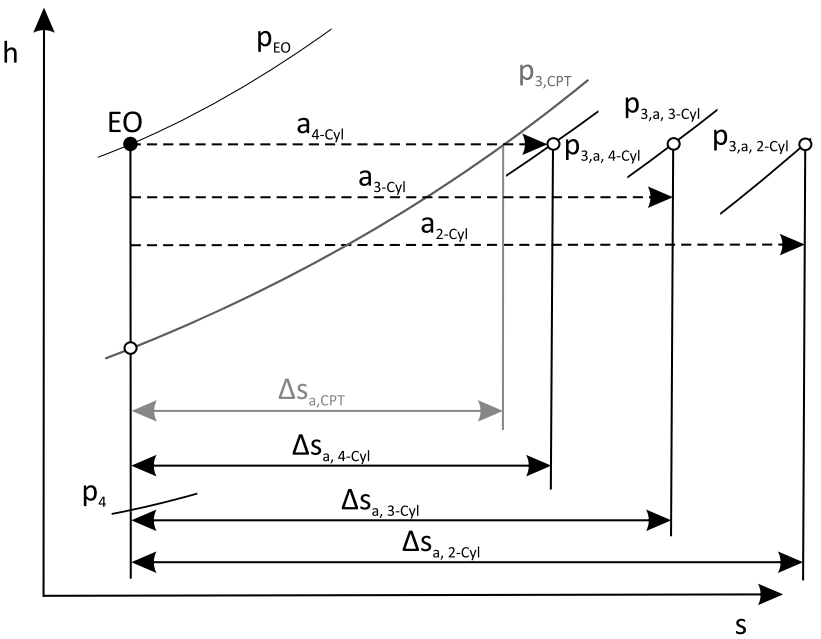

Fig. 11 The very first exhaust process and number of cylinders

With regard to a diesel engine, the case with $50 \mathrm{mg}$ injection quantity would be a realistic operating point at this boost pressure.

Another aspect is the boost pressure. Figure 13 shows the results with a lower boost pressure of 1.5 bar. The lambda values are similar to those in Fig. 12. With regard to the shape of the curves, similar tendencies as at a boost pressure of 2.5 bar can be seen again, but the boost pressure reduction itself also shifts the curve shapes to higher volumes.

Considering the stoichiometric case, the differences of the four- and three-cylinder engine can only be seen with an exhaust volume of more than 11 and also the two-cylinder engine may have a similar PMEP. In the range from 0 to 0.51 of exhaust volume, the PMEP is at a similar level. The left plot corresponds to a typical diesel operating point. Different pumping losses as a function of the number of cylinders are therefore unavoidable in the case of actually executable exhaust volumes.

Now, it is also recognizable that the turbocharging of diesel and gasoline engines is fundamentally different in this respect. Due to the need for excess air and recirculated exhaust gas, the diesel engine always requires considerably higher boost pressure than a stoichiometric operated gasoline engine. The differences become clear when the right image from Fig. 13 is compared with the image in the centre of Fig. 12. Although the fuel mass is not identical, this comparison symbolizes the differences between diesel and gasoline engines in terms of the number of cylinders.

All of these results were generated with a constant turbocharger efficiency of $49 \%$. With regard to pumping losses, lower turbocharger efficiencies can be compared with higher lambda values. The turbine must be of a smaller size and has to produce a higher pressure ratio in the exhaust stroke. Figure 14 shows the effects of a lower turbocharger efficiency by the example of the operating point with 2.5 bar boost 

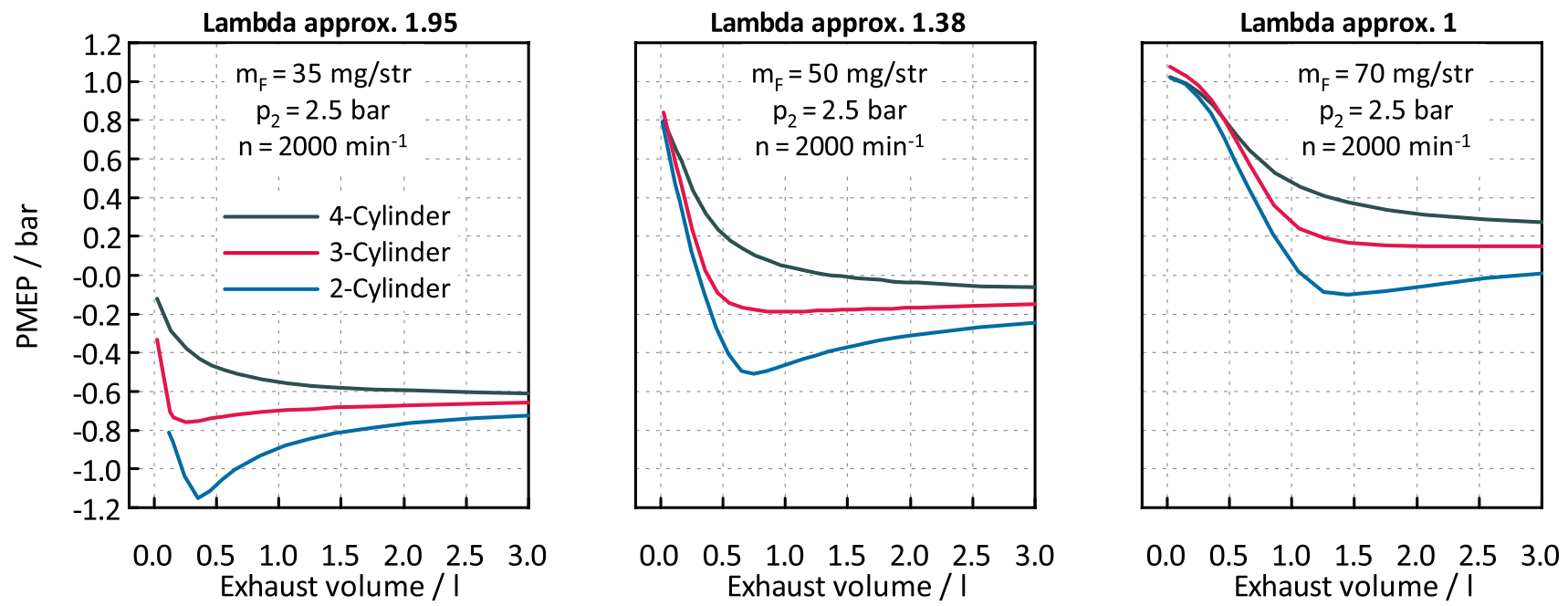

Fig. 12 PMEP depending on cylinder number, exhaust volume and lambda, boost pressure $=2.5 \mathrm{bar}$
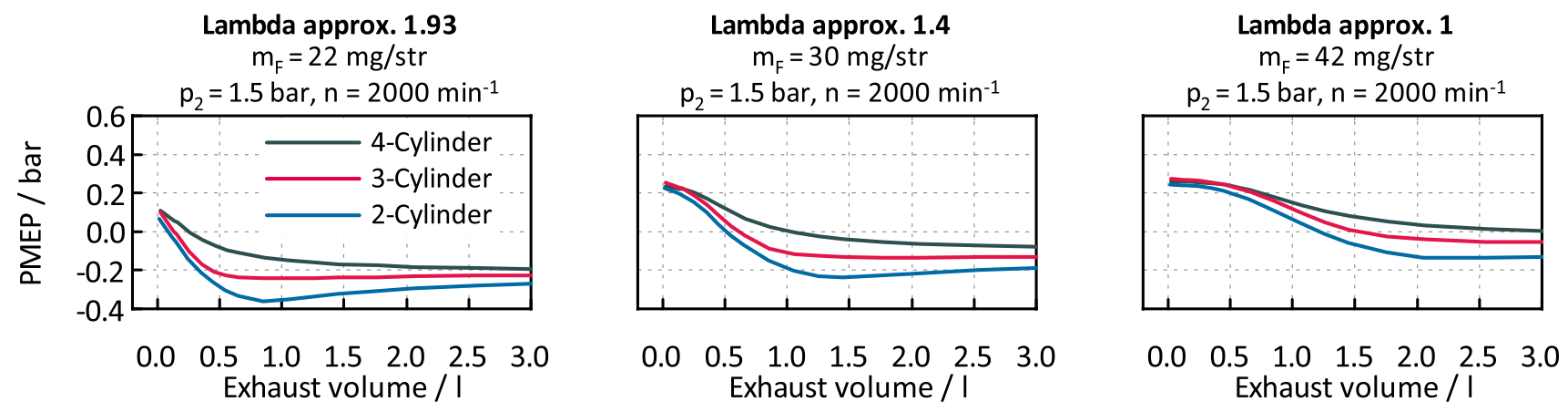

Fig. 13 PMEP depending on cylinder number, exhaust volume and lambda, boost pressure $=1.5 \mathrm{bar}$
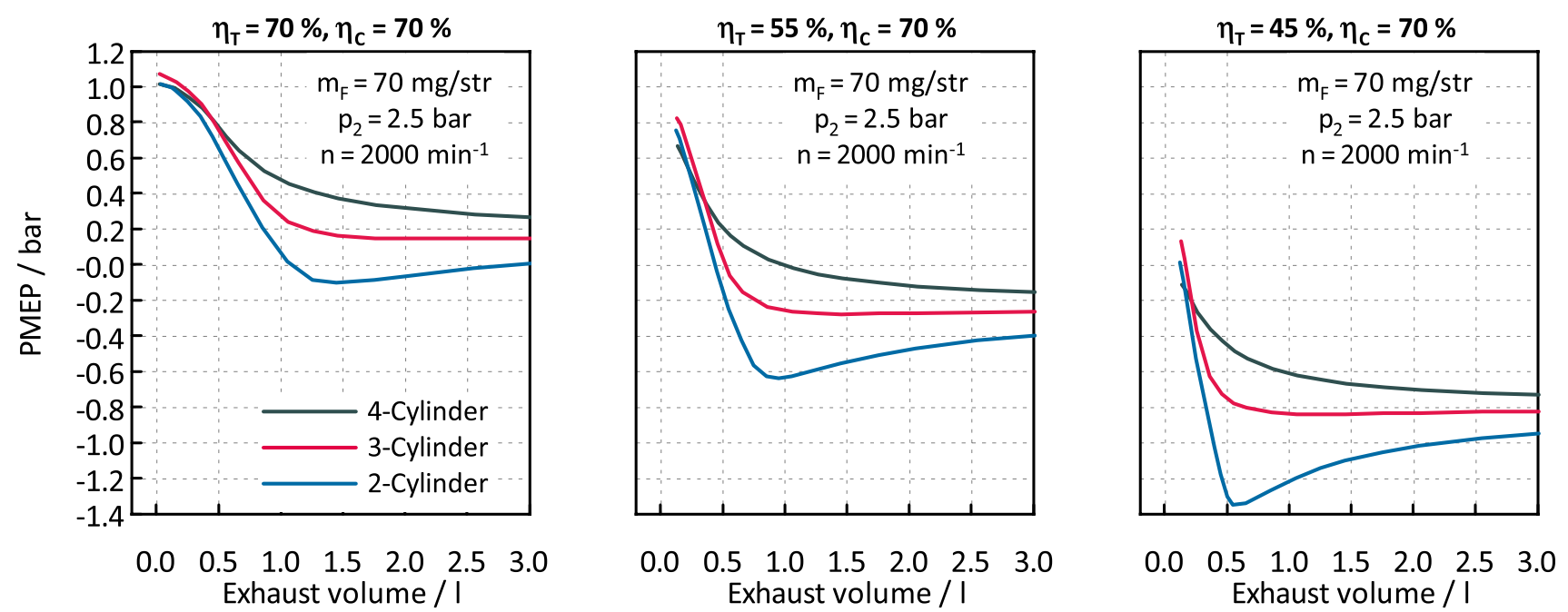

Fig. 14 PMEP depending on cylinder number, exhaust volume and $\eta_{\mathrm{TC}}$, boost pressure $=2.5$ bar, lambda $=1$ 
pressure and lambda $=1$. The total turbocharger efficiencies are $49 \%, 38.5 \%$ and $31.5 \%$. There are significant differences between the cylinder numbers at low turbocharger efficiencies, even with small exhaust volumes.

Therefore, the aspect explained for the diesel engine is also of crucial importance for a stoichiometric operated gasoline engine with low turbocharger efficiencies. Particularly in gasoline engines, which are still predominantly equipped with wastegate turbochargers, a poor turbocharger efficiency is to be expected in many operating points. The deterioration of the turbocharger efficiency has a double effect, especially on the two-cylinder engine, since the maximum of the pumping losses probably moves in the direction of the existing volume (depending on the design).

Taking an exhaust volume of 0.51 as an example, reducing turbine efficiency from 70 to $45 \%$ on the four-cylinder engine results in a reduction of 1.22 bar in PMEP. By contrast, this difference on the two-cylinder engine is 1.96 bar. For comparison, the difference using constant pressure turbocharging ( 501 , not shown) is 0.98 bar (no longer dependent on the number of cylinders).

\section{Experimental investigations}

\subsection{Construction}

To verify the results of the simulation, the pumping losses were of major interest in these experimental studies. In addition, a way to determine the turbocharger efficiency should also be found. This is an uncertain factor and was always kept constant in the previous simulations. In reality, stronger pulsations (pulse turbocharging) could lead to worse turbine efficiencies. A low-pressure indication was inserted upstream and downstream the high-pressure turbine (Fig. 15). With this measurement setup, it is possible to determine the instantaneous pressure both at the turbine inlet and at the turbine outlet to tune the simulation accordingly.

Exhaust volume was also varied in the measurements to confirm the simulations. The starting point was the base exhaust system of the four-cylinder engine. This system consists of the four-cylinder manifold and the HP-EGR radiator (see Fig. 16). Only the high-pressure stage TC can be seen in the picture. The low-pressure stage would be mounted on the visible front flange.

To represent constant pressure turbocharging, the EGR section was removed and a plenum with a volume of 3.511 was attached instead (in the picture right). From the plenum, there is no connection to the HP-EGR system which was closed. As can be seen in the picture, the connecting pipe from the manifold to the plenum is much longer than in the base system between the manifold and the HP-EGR cooler. Such a long pipe was not a thermodynamic desire, but had to be accepted

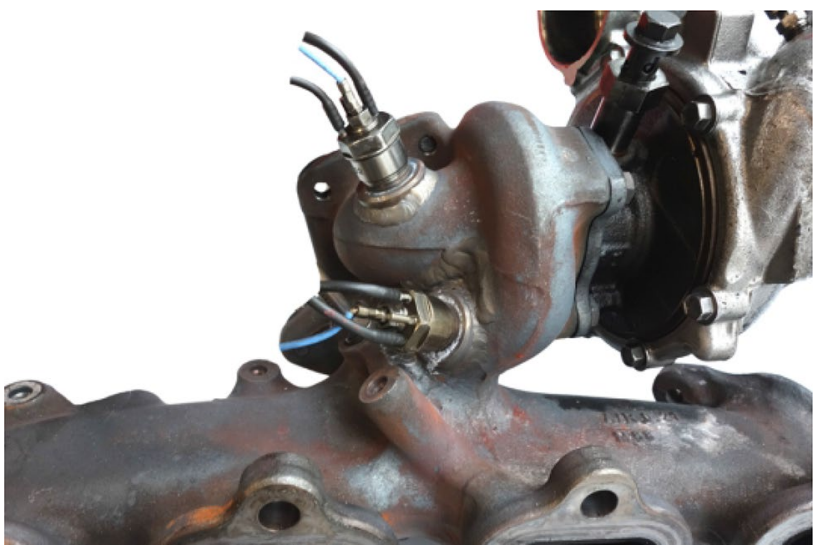

Fig. 15 LP-indication of the HP turbine, up- and downstream

due to the installation conditions on the engine. The influence of the long pipe is discussed separately in the results.

To realize the smallest possible volume, the four-cylinder manifold was truncated after the two inner cylinders and welded. In this way, the manifold volume of the other two cylinders and the entire HP-EGR system was eliminated. This exhaust volume represents the ideal (realizable) pulse turbocharging of a two-cylinder engine.

The total exhaust volumes of the different variants can be read from Fig. 16. In addition to the known simulation results, a two-cylinder variant with a turbocharger efficiency of $37.7 \%$ is added. The actual efficiencies of the measurements are more likely to be in that range. Accordingly, the PMEP is expected to be smallest for the two-cylinder variant with the small manifold and a reduced turbocharger efficiency of $37.7 \%$.

\subsection{Methodology for determining turbocharger efficiency}

Determining turbocharger efficiency based on measurement data is not straightforward. To calculate the overall turbocharger efficiency, the pressures up- and downstream compressor and turbine and the temperatures upstream compressor and turbine as well as the mass flows must be known. The mean values of these quantities are standard measuring technology. At low numbers of cylinders and the associated high pulsations in the exhaust manifold, the mean values are not significant.

The turbocharger efficiency can be calculated according to Eq. 1:

$\eta_{\mathrm{TC}}=\frac{\dot{m}_{\mathrm{C}} \cdot c_{p, \mathrm{C}} \cdot T_{1}}{\dot{m}_{\mathrm{T}} \cdot c_{p, \mathrm{~T}} \cdot T_{3}} \cdot \frac{\left(\frac{p_{2}}{p_{1}}\right)^{\frac{\kappa_{\mathrm{C}-1}}{\kappa_{\mathrm{C}}}}-1}{1-\left(\frac{p_{4}}{p_{3}}\right)^{\frac{\kappa_{\mathrm{T}-1}}{\kappa_{\mathrm{T}}}}}$.

The determination of a single efficiency (turbine or compressor) also requires the temperatures after compressor or 


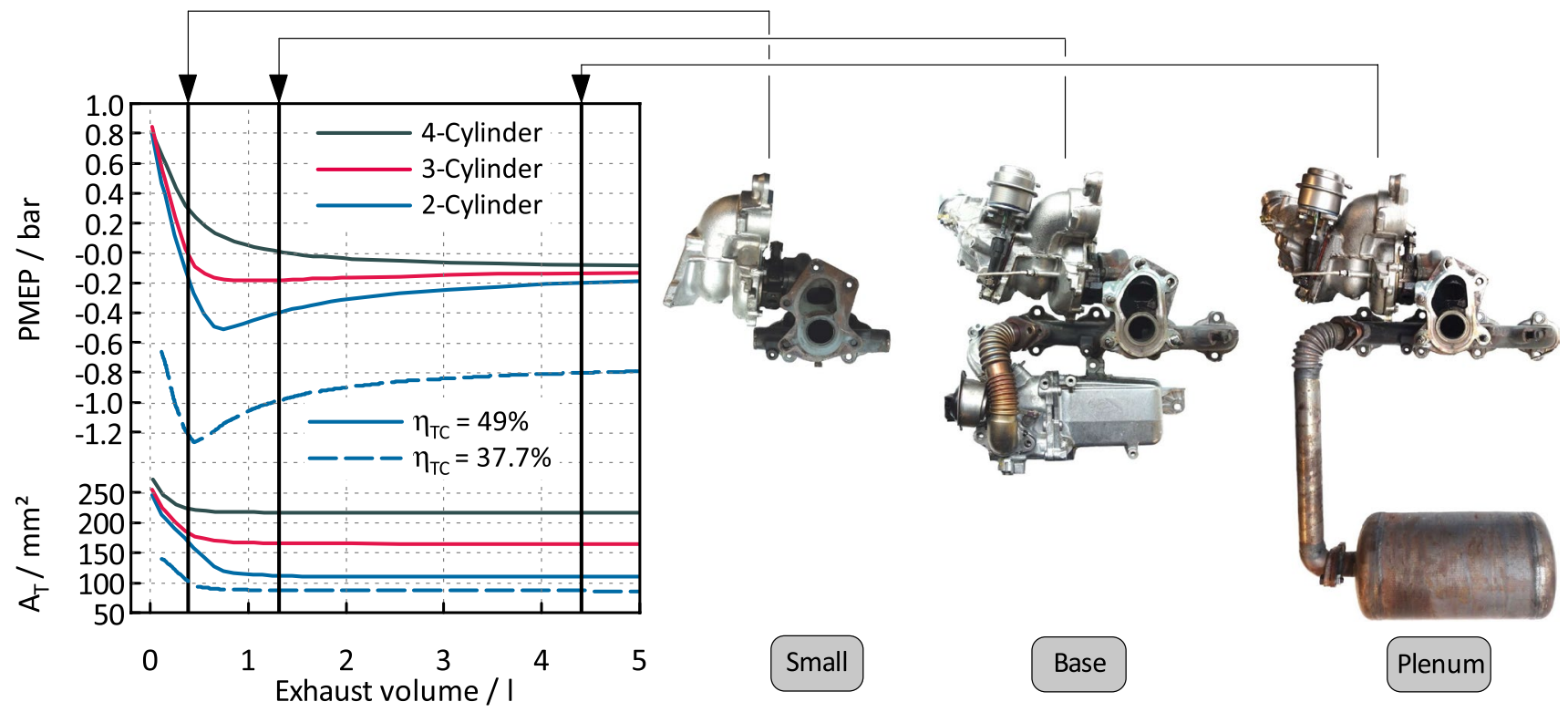

Fig. 16 Different exhaust systems used on the test carrier, $2000 \mathrm{~min}^{-1}, m_{\mathrm{F}}=50 \mathrm{mg}, p_{2}=2.5$ bar

after turbine (Eqs. 2, 3). Both temperatures are very critical to measure and sensitive to heat losses and environmental conditions. Thus, the turbine efficiency is not determined in this way. More commonly, the calculation is based on the work of the compressor and the power balance of turbine and compressor (Eq. 4). Here, the mechanical efficiency is already included, it is not just an isentropic efficiency. Both efficiencies (Eqs. 2, 4) are very sensitive to a measurement error of the temperature $T_{2}$.

$\eta_{s, \mathrm{C}}=\frac{\left(\frac{p_{2}}{p_{1}}\right)^{\frac{{ }{ }_{\mathrm{C}}-1}{{ } \mathrm{C}}}-1}{\frac{T_{2}}{T_{1}}-1}$

$\eta_{s, \mathrm{~T}}=\frac{1-\frac{T_{4}}{T_{3}}}{1-\left(\frac{p_{4}}{p_{3}}\right)^{\frac{\kappa_{\mathrm{T}}-1}{{ }^{\mathrm{T}}}}}$

$\eta_{\mathrm{T}}=\frac{\dot{m}_{\mathrm{C}} \cdot c_{p, \mathrm{C}} \cdot\left(T_{2}-T_{1}\right)}{\dot{m}_{\mathrm{T}} \cdot c_{p, \mathrm{~T}} \cdot T_{3} \cdot\left(1-\left(\frac{p_{4}}{p_{3}}\right)^{\frac{\kappa_{\mathrm{T}-1}}{\kappa_{\mathrm{T}}}}\right)}$

In the following, the methodology for determining the turbocharger efficiency is presented. Only the overall turbocharger efficiency was considered, as it can be determined much more accurately than a single efficiency. First, the measurement must be done in the right way.

\subsubsection{Measurement with closed turbine bypass}

Meaningful evaluations of a turbocharger efficiency as a function of the exhaust volume cannot be realized with the strategy of a controlled boost pressure. With this approach, the mass flow passing the high-pressure turbine through the turbine bypass would be different. And exactly this mass flow is not determinable. If the mass flow through a turbine cannot be determined, it is also impossible to calculate a turbocharger efficiency. Against this background, the only option is to always keep the turbine bypass closed. The boost pressure is thus determined by the engine speed and injection quantity, which is why no comparison can be made with the same boost pressures at the same injection quantity.

A direct comparison of the different exhaust volumes at the same engine speed can be seen in Fig. 17. It is noticeable that almost the same boost pressure can be achieved with the base manifold and the large additional plenum. Only with the small manifold, a significantly higher boost pressure can be generated. The volume of the base manifold is already so large that a further increase has only a minor effect on the boost pressure (compare Fig. 16, necessary turbine size versus exhaust volume).

The PMEP can be increased by about 0.2 bar with the additional plenum compared to the base exhaust system. The differences between the variants additional plenum and small manifold are up to 0.9 bar, in which case it must be taken into account that the boost pressures are not equal.

The measurement data of the indication is shown in Fig. 18. Different injection quantities are required to achieve the same boost pressure. The traces of the low-pressure 


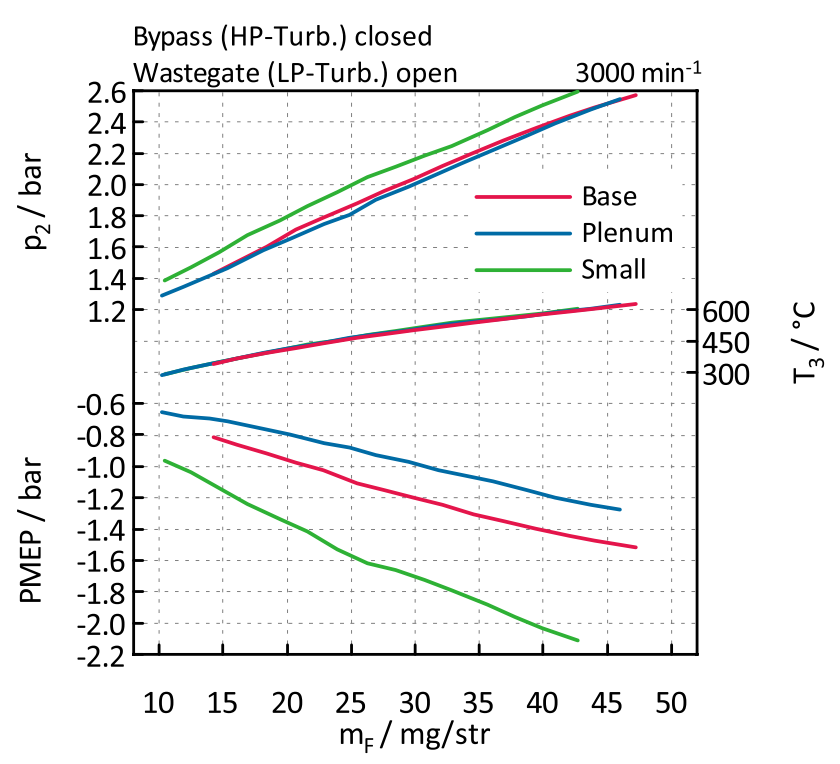

Fig. 17 Load variation with HP-TC at $3000 \mathrm{~min}^{-1}$

indication are denoted in the left picture with $p_{\text {usHP-T }}$ as the pressure upstream the high-pressure turbine and with $p_{\text {dsHP-T }}$ as the pressure downstream the high-pressure turbine.

With the large additional plenum, the charging system should be shifted more towards constant pressure turbocharging. Therefore, a homogenization of the pressure pulsations would be expected. As can be seen in the picture, the pressure pulsations with the large additional plenum are even larger compared to the base manifold. These oscillations can be explained by the long connecting pipe from the exhaust manifold to the plenum (see Fig. 16), which has also been confirmed by simulations. Nevertheless, it can be seen that at the beginning of the exhaust process, a higher pressure prevails in the exhaust manifold, so the positive thermodynamic effect is still present.

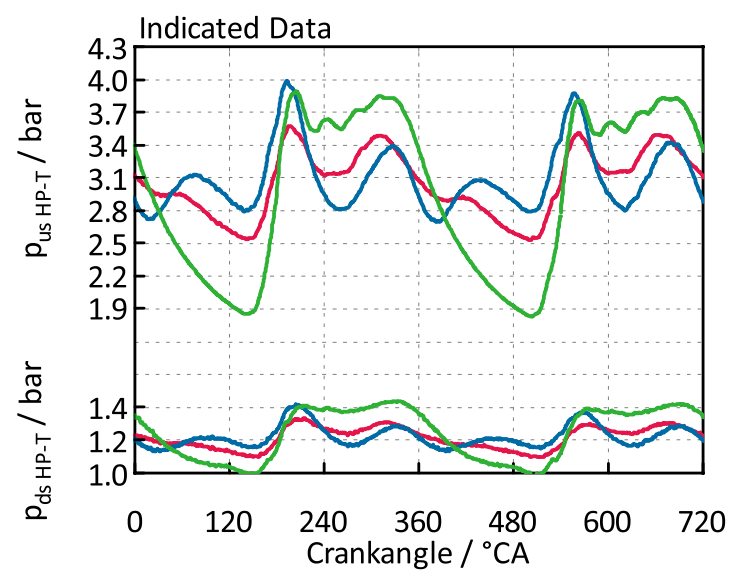

As expected, the pressure pulsations with the small manifold are significantly higher than with the base manifold. The pressure at the beginning of the exhaust process is very low, the entropy increase in the blow-down phase is therefore high.

The right picture shows the gas exchange loops. Due to the almost identical pressure conditions in the intake phase, the differences in PMEP are clearly visible on the exhaust stroke. With the additional plenum, the pressure in the exhaust decreases during the exhaust stroke, which is why the pumping losses are lower compared to the base manifold. This circumstance must occur because the pressure in the blow-down phase is higher and the throttle losses are therefore lower.

If the pressure in the exhaust stroke did not drop, the turbine power and consequently the boost pressure would have to be higher, assuming the same turbocharger efficiencies.

The comparison of the gas exchange loops is not fair, as the injection quantities are different. In terms of a thermodynamically correct comparison with respect to the exhaust volume, the turbine size would have to be adapted, which is not simply realizable in the measurements. In this way, however, the desired boost pressure could be generated with the same injection quantity for all variants. Especially the differences between the variants with the plenum and the small manifold would decrease.

The measurements also showed the influence of the exhaust volume on the required turbine size, which has already been mentioned on the basis of simulations. A smaller exhaust volume will always lead to higher boost pressure with the same turbine size [6]. The turbine accumulates a higher back pressure during the exhaust stroke with a smaller exhaust volume. At this point, it is once again pointed out that the boost pressure achieved (with different exhaust volumes) does not allow any conclusions to be drawn on an efficiency.

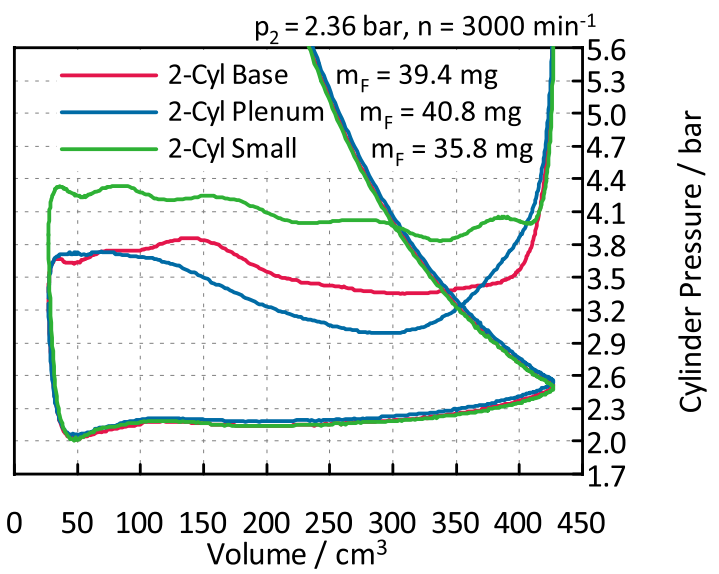

Fig. 18 Indicated data at reference points (same boost pressure) 
The question arises as to how the turbocharger efficiency can be determined. A meaningful efficiency calculation cannot be made with averaged pressures. Now one could calculate a turbine pressure ratio with the pressure profiles from the indication. However, the mass flow through the turbine (cycle resolved) remains unknown. It would be necessary to know the mass flow as a function of the turbine pressure ratio, which is only possible to a very limited extent with the turbocharger data of a manufacturer.

Furthermore, the temperature in the exhaust manifold through the filling and emptying of the manifold and the expansion in the cylinder during the exhaust process is not constant and therefore unknown as a cycle based value.

\subsubsection{Combination of measurement and simulation}

Against this background, a combination of measurement data and simulation was considered the only way to determine turbocharger efficiencies at the measured operating points.

For this purpose, a turbocharger full model was used. Turbine maps are only available in a very limited operating range due to the measurement method on the hot gas test bench [2, 7]. Therefore, an extrapolation must be performed to simulate a real engine process. There are many publications on the efficiency of the turbine under pulsating conditions. In these investigations, turbine extrapolation had a minor focus, so an extrapolation (efficiency) with standard parameters was used and the turbine efficiency was changed via an offset parameter according to the measurement results.

To achieve the best possible correspondence between the pressure traces of simulation and measurement, it is necessary to adapt the simulation models to the measured data. To achieve a good agreement with the measurement results, considerable effort is required. Even with the supposedly

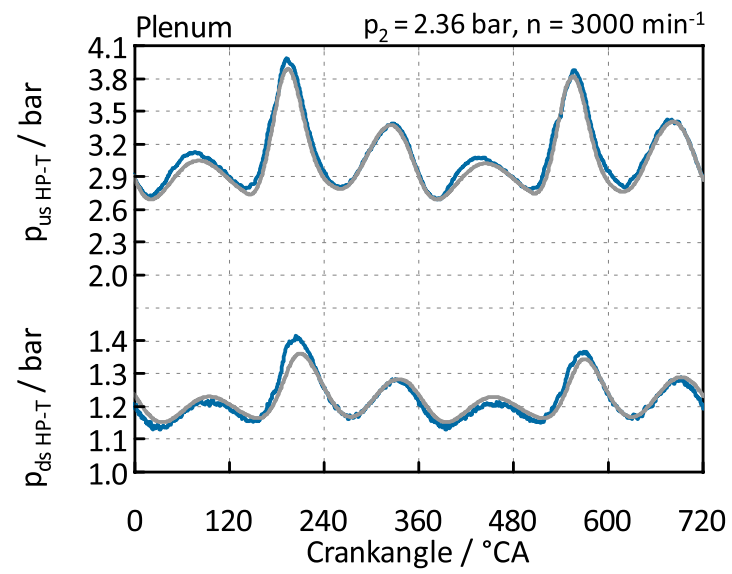

simplest exhaust system, the small manifold, tuning is difficult. In addition to the geometric dimensions, the flow capacity of the turbine remains an open point. The flow capacity is very different from a orifice and also dependent on the turbocharger speed, as can be seen in [2].

Particularly in the case of the small manifold, large differences in the turbine pressure ratio occur, in which case the flow capacity has the greatest influence. Regarding the geometrical characteristics, the base exhaust system is the most complex, even the diameter and the length after the EGR cooler have decisive effects on the pressure trace.

If, after tuning the flow capacity and the geometrical dimensions, a correspondence of the pressure traces is achieved, it can also be assumed that the mass flow through the turbine meets the reality. This mass flow, not known from the measurement, is one major reason why the turbocharger efficiency cannot be calculated from the measured data.

Figure 19 shows a comparison of measurement and simulation for the exhaust system with plenum. The left image contains the pressures upstream and downstream the high pressure turbine, the right image shows the associated gas exchange loops.

In addition to the pressure, the temperature also plays a decisive role, but this can only be adapted to the average values from the measurements. The measured temperature $\left(T_{3 . \text { Meas }}\right)$ and the simulated and sensor-modeled temperature $\left(T_{3 . \text { Sim }}\right)$ are shown in the images.

The interesting part of these simulations is the calculated turbocharger efficiency, which is shown in the picture. If the pressure traces and the mean temperature match and the boost pressure is identical, the efficiency required in the simulation can be considered as the true efficiency of the experimental investigation.

Figure 20 shows the turbocharger efficiencies based on load variations in two-cylinder operation at $3000 \mathrm{~min}^{-1}$ and in four-cylinder operation at $1500 \mathrm{~min}^{-1}$. The high pressure

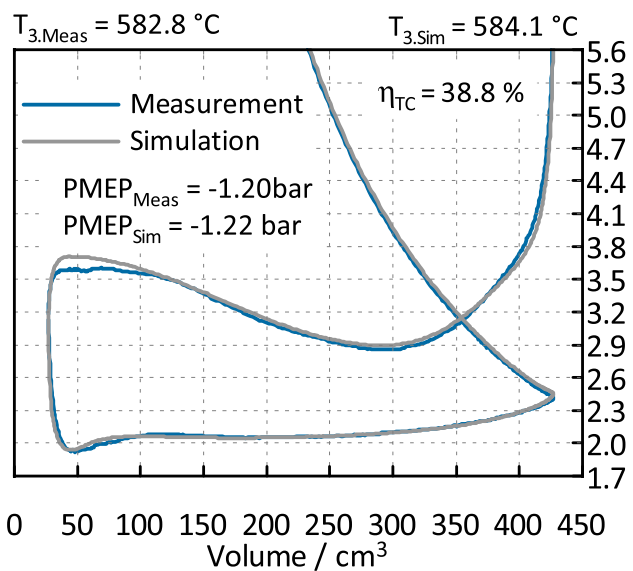

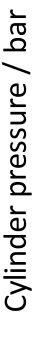

Fig. 19 Comparison of simulation and measurement 
pulsations with the small manifold reduced turbocharger efficiency by approximately up to $2 \%_{\mathrm{Pt}}$ compared to the base exhaust system. This was a behaviour that was predictable and in line with expectations. For a larger exhaust volume, a higher turbocharger efficiency would generally be expected, but the results (plenum) certify an efficiency that is lower by approximately $0.4 \%_{\mathrm{Pt}}$. Given the strong pressure oscillations, this seems quite plausible.

The advantageous PMEP with the large plenum compared to the base exhaust system is therefore not a result of a higher turbocharger efficiency, but only due to the more efficient harnessing of the blow-down energy.

In four-cylinder operation, the turbocharger efficiency was $2 \%_{\mathrm{Pt}}$ higher than in two-cylinder operation with the same exhaust system. In contrast to the two-cylinder comparison, this difference in efficiency cannot only be attributed to the

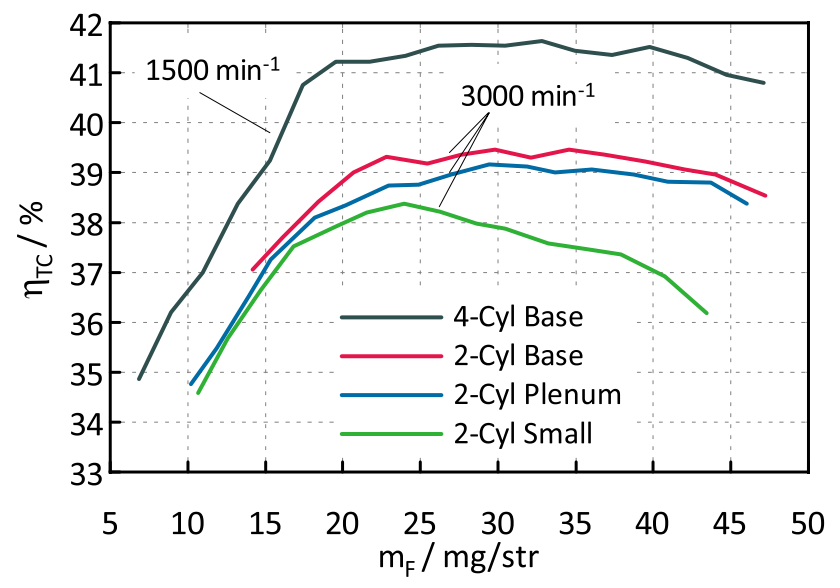

Fig. 20 TC efficiencies determined with simulation turbine side, it could also occur as a higher compressor efficiency due to the more uniform mass flow. Compressor efficiency could be calculated with averaged pressure upstream and downstream the compressor, but the temperatures are too sensitive to environmental influences.

\subsection{Analysis of losses}

The differences in PMEP can be explained by two effects, the discharge process (blow-down phase) and the turbocharger efficiency. In the previous simulations, the effect of the exhaust volume on the PMEP was quantified. Based on the measurement results, the question arises what influence the turbocharger efficiency has on the PMEP at all. In addition, it must be taken into account that higher boost pressures are achieved with the small manifold and the same injection quantities.

In the simulation, it is possible to change the turbine size so that the same boost pressures are achieved with all exhaust systems (based on the injection quantity). Only with a modified turbine cross-section, a fair comparison is possible regarding the PMEP. The results of this procedure are shown in Fig. 21. The left picture shows the turbocharger efficiencies and PMEP of the adapted simulation models with the additional plenum and the small manifold. Based on the model with the small manifold, the turbine size (via a multiplier in the full model) was increased to reach the boost pressure of the additional plenum variant. The turbocharger efficiency was maintained or slightly changed in the map, to achieve the same efficiency after this operating point shift in the turbocharger map.

Then, the variant followed with the adjusted turbine size and additionally a turbocharger efficiency, which

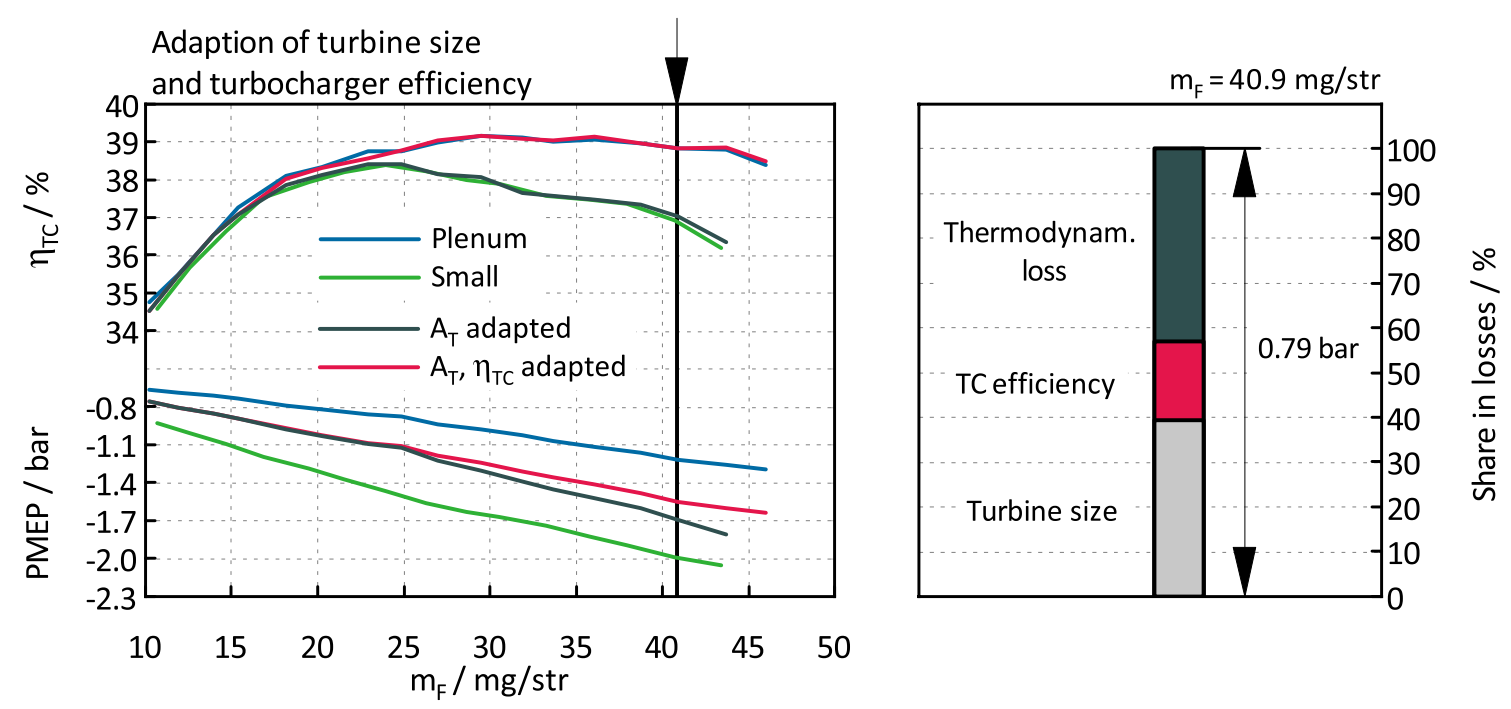

Fig. 21 Influences on PMEP with different exhaust systems 
corresponds to the variant with the plenum. Only after adaptation of these two variables, the effect of the exhaust volume or the thermodynamic loss in the discharge process can be seen. Now, the partition of the individual (difference) losses between the systems with large and small exhaust volumes can be considered in more detail.

On the right side of the picture, such an analysis is shown for an exemplary injection quantity of $40.9 \mathrm{mg}$. At this operating point, there is a difference in PMEP of 0.79 bar. Almost $40 \%$ of this difference is due to the non-adapted turbine size. Considering only the measurements with the different pumping losses, one could assume that this is due to different turbocharger efficiencies. In reality, however, the efficiency of the turbocharger makes up the smallest part (approx. 18\%). The largest share is attributed to the exhaust volume and the associated discharge process itself with approx. $43 \%$. This (difference) loss is indicated in the picture with thermodynamic loss.

\section{Summary}

The influence of the number of cylinders on turbocharging, in particular the turbine side, was the subject of these investigations. Using 1D-CFD simulations, experimental investigations and theoretical thermodynamic considerations, the differences could be quantified and theoretically explained.

The inline three-cylinder engine is widely considered to be the best engine in terms of turbocharging. The main advantage of the three-cylinder engine compared to higher cylinder numbers is that the ignition intervals are long enough so that no mutual influence of the exhaust operations of two cylinders can take place. For this reason, a positive scavenging pressure gradient is possible, which increases the cylinder filling and reduces the risk of knocking due to the lower residual gas content. In addition, a large scavenging mass in the low-end range can be used to increase the mass flow through the turbine. However, all these arguments are less relevant for diesel engines.

The simulations showed higher pumping losses at lower cylinder numbers in principle, even with the same turbocharger efficiencies. Based on theoretical thermodynamic considerations, it was explained that these differences are caused by a throttling process in the first exhaust phase (blow-down phase) due to the different exhaust gas back pressures at this time depending on the number of cylinders.

For the experimental investigations, a four-cylinder engine was operated as a two-cylinder engine by the use of modified camshafts. Different exhaust volumes were also used to verify the simulations.

The smallest possible two-cylinder exhaust manifold resulted in a 0.8 bar higher PMEP than the largest exhaust volume. An accurately adjusted 1D-CFD model was used to determine the turbocharger efficiencies of the measurements and to provide a breakdown of the differences in pumping losses. As a result, it has been found that the turbocharger efficiency has the least amount of the large differences in the PMEP.

In view of the results, it should be noted that by comparison of the PMEP with different cylinder numbers or different exhaust volumes, no conclusions can be drawn on the turbocharger efficiency. Furthermore, it must be noted that a change in the exhaust volume may also causes a change in the necessary turbine size. Without adjusting the turbine size, wrong conclusions could be drawn.

Especially in diesel engines, the results have shown that a four-cylinder engine can achieve the lowest pumping losses. However, it was also shown that the conditions on a stoichiometric operated gasoline engine are completely different. Under certain conditions (boost pressure, lambda, turbocharger efficiency), the pumping losses of a two-cylinder engine are similar to the pumping losses of a four-cylinder engine, and the three-cylinder engine has much better scavenging and cylinder filling. In this case (gasoline engine), the three-cylinder engine might be considered as optimum in terms of turbocharging, but not with regard to diesel-specific boost pressures and lambda values. In diesel engines, three-cylinder engines and especially two-cylinder engines have a significant disadvantage in terms of pumping losses compared to four-cylinder engines.

Acknowledgement Open access funding provided by Graz University of Technology.

Open Access This article is distributed under the terms of the Creative Commons Attribution 4.0 International License (http://creativeco mmons.org/licenses/by/4.0/), which permits unrestricted use, distribution, and reproduction in any medium, provided you give appropriate credit to the original author(s) and the source, provide a link to the Creative Commons license, and indicate if changes were made.

\section{References}

1. Aymanns, R., Scharf, J., Uhlmann, T., Lückmann, D.: A Revision of Quasi Steady Modelling of Turbocharger Turbines in the Simulation of Pulse Charged Engines. Aufladetechnische Konferenz Dresden (2011)

2. Baines, N., Fredriksson, C.: The Simulation of Turbocharger Performance for Engine Matching. Motorprozesssimulation und Aufladung, Berlin (2007)

3. Boxberger, V., Baar, R., Gern, M., Zimmermann, R.: ZweiZylinder vs. Vier-Zylinder-Analyse der Turbinenströmung im pulsierenden Betrieb. Aufladetechnische Konferenz Dresden (2015)

4. Brüstle, C., Wittwer, U., Lester, L., Davis, R.: Neander Dtorque 111, the First Turbodiesel Outboard with Dual Crankshaft Technology. In: 26th Aachen Colloquium Automobile and Engine Technology (2017) 
5. Cuniberti, M., Micelli, D., Stroppiana, A., et al.: Charging System for a Small Bi-cylinder Engine: The TwinAir Experience. Aufladetechnische Konferenz, Dresden (2011)

6. Kellermayr, G.: Innermotorische Optimierungsmaßnahmen am Pkw-Dieselmotor hinsichtlich zukünftiger $\mathrm{CO}_{2}$-Ziele und Emissionsgesetzgebungen. TU Graz, Dissertation (2019)

7. Lüddecke, B., Filsinger, D., Bargende, M.: Betriebsverhalten von Abgasturboladern. Motorentechnische Zeitschrift (2017)

8. Pischinger, R., Klell, M., Sams, T.: Thermodynamik der Verbrennungskraftmaschine, 3, Auflage, pp. 315-317. Springer, Wien (2009)
9. Pucher, H., Zinner, K.: Aufladung von Verbrennungsmotoren, 4th edn, pp. 28-32. Springer, Berlin (2012)

10. Steyr Motors M12.: Product Page. http://www.steyr-motors.com/ automotive/unit-injection-engines/m12-ui-2-cylinder-unit-injec tion-engine

Publisher's Note Springer Nature remains neutral with regard to jurisdictional claims in published maps and institutional affiliations. 